\title{
Assessment of Smoke Contamination in Grapevine Berries and Taint in Wines Due to Bushfires Using a Low-Cost E-Nose and an Artificial Intelligence Approach
}

\author{
Sigfredo Fuentes ${ }^{1}\left(\mathbb{D}\right.$, Vasiliki Summerson ${ }^{1} \oplus$, Claudia Gonzalez Viejo ${ }^{1, *} \oplus$, Eden Tongson ${ }^{1}$, \\ Nir Lipovetzky ${ }^{2}\left(\mathbb{D}\right.$, Kerry L. Wilkinson ${ }^{3,4}{ }^{-}$, Colleen Szeto ${ }^{3,4}{ }^{(-)}$and Ranjith R. Unnithan ${ }^{5}$ \\ 1 Digital Agriculture, Food and Wine Sciences Group, School of Agriculture and Food, Faculty of Veterinary \\ and Agricultural Sciences, The University of Melbourne, Parkville, VIC 3010, Australia; \\ sfuentes@unimelb.edu.au (S.F.); vsummerson@student.unimelb.edu.au (V.S.); \\ eden.tongson@unimelb.edu.au (E.T.) \\ 2 School of Computing and Information Systems, Melbourne School of Engineering, The University of \\ Melbourne, Parkville, VIC 3010, Australia; nir.lipovetzky@unimelb.edu.au \\ 3 School of Agriculture, Food and Wine, The University of Adelaide, Waite Campus, PMB 1, \\ Glen Osmond, SA 5064, Australia; kerry.wilkinson@adelaide.edu.au (K.L.W.); \\ colleen.szeto@adelaide.edu.au (C.S.) \\ 4 The Australian Research Council Training Centre for Innovative Wine Production, PMB 1, \\ Glen Osmond, SA 5064, Australia \\ 5 School of Engineering, Department of Electrical and Electronic Engineering, The University of Melbourne, \\ Parkville, VIC 3010, Australia; r.ranjith@unimelb.edu.au \\ * Correspondence: cgonzalez2@unimelb.edu.au; Tel.: +61-412055704
}

Received: 24 August 2020; Accepted: 4 September 2020; Published: 8 September 2020

check for updates

\begin{abstract}
Bushfires are increasing in number and intensity due to climate change. A newly developed low-cost electronic nose (e-nose) was tested on wines made from grapevines exposed to smoke in field trials. E-nose readings were obtained from wines from five experimental treatments: (i) low-density smoke exposure (LS), (ii) high-density smoke exposure (HS), (iii) high-density smoke exposure with in-canopy misting (HSM), and two controls: (iv) control (C; no smoke treatment) and (v) control with in-canopy misting (CM; no smoke treatment). These e-nose readings were used as inputs for machine learning algorithms to obtain a classification model, with treatments as targets and seven neurons, with $97 \%$ accuracy in the classification of 300 samples into treatments as targets (Model 1). Models 2 to 4 used 10 neurons, with 20 glycoconjugates and 10 volatile phenols as targets, measured: in berries one hour after smoke (Model 2; $\mathrm{R}=0.98 ; \mathrm{R}^{2}=0.95 ; \mathrm{b}=0.97$ ); in berries at harvest (Model 3; $\mathrm{R}=0.99$; $\mathrm{R}^{2}=0.97 ; \mathrm{b}=0.96$ ); in wines (Model $4 ; \mathrm{R}=0.99 ; \mathrm{R}^{2}=0.98 ; \mathrm{b}=0.98$ ). Model 5 was based on the intensity of 12 wine descriptors determined via a consumer sensory test (Model 5; $R=0.98 ; R^{2}=0.96$; $\mathrm{b}=0.97$ ). These models could be used by winemakers to assess near real-time smoke contamination levels and to implement amelioration strategies to minimize smoke taint in wines following bushfires.
\end{abstract}

Keywords: climate change; machine learning; electronic nose; smoke taint; wine sensory

\section{Introduction}

When bushfires occur within the grape growing season, vineyards can be affected at critical stages (véraison to harvest) [1], which could result in different levels of smoke contamination in berries and smoke taint in wines [2,3]. The intensity, number, and severity of bushfires are increasing due to climate change as well as the window of opportunity [4]. 
The growing concerns in Australia regarding bushfire scale and frequency are shared by wine regions around the world, including the USA, Canada, South Africa, Portugal, Chile, and others [5]. To assess the potential risk of smoke taint, the industry typically relies on the analysis of grape samples by commercial laboratories to quantify smoke taint marker compounds (i.e., volatile phenols and their glycoconjugates), but this can be prohibitively expensive for some producers [6,7]. Alternatively, grapes can be harvested and vinified so that sensory analysis can be conducted in-house. However, depending on the timing of smoke exposure, these approaches may not inform decision-making within the time-constraints of vintage.

To date, there has been little research into the use of affordable in-field technology to assess grapevine smoke contamination. Recently, the authors' group published a study evaluating short-range remote sensing in the thermal and near-infrared spectrum, combined with machine learning, as a novel approach to assessing smoke contamination in grapevine leaves, berries, and wines, with high levels of accuracy [5]. These tools may support rapid decision-making, enabling the implementation of management strategies that reduce the risk of contamination carrying over into wine, as smoke taint.

Electronic noses (e-nose) are comprised of an array of metal oxide semiconductor sensors (MOS) sensitive to different gases that can measure a variety of volatiles in the environment [8]. Early developments of e-noses involve arrays of 5-8 tin-oxide type of MOS sensors, requiring the use of sealed chambers and/or a complete setup of different devices to heat the sample and obtain headspace to be injected in the e-nose chamber, which has made the e-noses non-portable as they require a laboratory setup $[9,10]$. Some studies have explored different signal extraction methods, such as the Lorentzian model, which has resulted in a powerful and rapid-response technique [11]. Ayhan et al. [12] explored the fluctuation-enhanced sensing method to detect and classify gases with improved accuracy when developing classification models using machine learning algorithms. Some applications include medical diagnostics [13], space shuttles and stations [14-16], crime and security [17], and food and beverages, such as rapeseed to detect volatile compounds in pressed oil [18], wine [19], and beer [20], among others. The latter study describes a low-cost e-nose developed with nine gas sensors to assess the aroma profile of beers coupled with machine learning modeling. Examples of the implementation of e-noses for food science can be found from early literature reviews [21] through the implementation of disease diagnostics [22], more recent applications to assess food quality [23], meat quality assessment [24], for food control [23], assessment of food authentication and adulteration [25], and for the wine industry [26-30]. However, the e-noses used in the past range in complexity, accessibility to users, and cost.

Low-cost e-noses can be used in the field to assess smoke contamination levels coupled with the internet of things (IoT) for data transmission and analysis from different locations or nodes within vineyards. However, a more efficient approach could be to mount e-noses to assess gases in different parts of vineyards and to generate geo-referenced maps of these gases on unmanned terrestrial vehicles (UTV), robots [31], or unmanned aerial vehicles (UAV) [32]. The levels of smoke-related contaminants could be modeled using machine learning algorithms to infer the levels of contaminants in berries, and therefore, the risk of smoke taint in the final wine. However, they could not be used to directly "sniff" these contaminants from bunches since smoke-derived volatile compounds are rapidly metabolized in berries, leading to the formation of glycoconjugates, which are odorless [2,5-7,33-35].

This study evaluated the potential for low-cost e-noses to be used to assess wines made from grapes exposed to different levels (densities) of smoke. The e-nose measurements were used as inputs in machine learning modeling strategies, and the concentrations of smoke taint marker compounds in berries and wines used as targets. Further, targets were obtained from a sensory analysis trial, during which consumers assessed the wines made from each treatment. In total, five machine learning models were created based on e-nose data to assess (i) the level of contamination in grapevines related to smoke exposure from wine samples using classification models (Model 1); (ii) to evaluate smoke-related compounds from wines, such as 20 glycoconjugates and 10 volatile phenols in berries after $1 \mathrm{~h}$ smoke (Model 2), (iii) smoke-related compounds in berries measured at harvest (Model 3), (iv) for wines made 
from treatments (Model 4), and (v) consumer sensory analysis using 12 wine descriptors (Model 5; Figure 1). The models obtained were of high accuracy, which could allow the implementation of this artificial intelligence (AI) technology in the winemaking process to assess the effect of ameliorating management techniques in the field (Model 1) through micro-vinifications, to assess the best timing for skin contact during fermentation for red wines, the addition of activated carbon to adsorb smoke-related compounds, wine filtration using membranes, reverse osmosis, and other commercial fining agents, among others [34,35].

Not only could the implementation of this technique help winemakers evaluate the different amelioration techniques mentioned above, but it could also monitor almost real-time changes in the aroma profiles of wine and assess which technology could best maintain a certain quality or style target.

This paper described how the e-nose was implemented for the different treatments and wine samples used and the specific machine learning algorithms used to develop five machine learning models with their respective analyses for accuracy and performance. A discussion on potential applications of the e-nose and models was also described for the wine industry to monitor and reduce smoke taint in wines.

\section{Materials and Methods}

\subsection{Description of Treatments and Wine Samples}

Field trials involving the application of smoke and/or in-canopy misting to Cabernet Sauvignon grapevines have been reported previously [3]. Briefly, three different smoke treatments were applied to vines (at approximately 7 days post-véraison): (i) low-density smoke exposure (LS), (ii) high-density smoke exposure (HS), and (iii) high-density smoke exposure, with in-canopy misting (HSM). Two controls were also included: (iv) a control without misting (C; no smoke treatment) and (v) a control with misting (CM; no smoke treatment). Treatments were applied to six adjacent vines, except for HSM, which was applied to five adjacent vines (i.e., one vine was missing). Smoke treatments involved exposure of grapevines to straw-derived smoke using a purpose-built tent for $1 \mathrm{~h}$. At least one buffer vine separated treatments. The wine was subsequently produced on a small scale (i.e., $\sim 5 \mathrm{~kg}$ per fermentation, performed in triplicate for each treatment), as described previously [3].

\subsection{Electronic Nose}

Wine samples were measured (in triplicate) using a portable, user-friendly, and low-cost e-nose, comprising nine different sensors, which were sensitive to different gases, as mentioned in Table 1, plus a humidity and temperature sensor (AM2320; Guangzhou Aosong Electronics Co., Ltd., Guangzhou, China). Sensor details have already been reported [20]. A total of $100 \mathrm{~mL}$ of wine was poured into a $500 \mathrm{~mL}$ beaker, and the e-nose was placed on top of the container for $1 \mathrm{~min}$ to capture the gases present in the sample. The e-nose was calibrated for 20-30 s before and after measuring each sample to reset the readings to baseline. Values from all sensors were automatically recorded in a comma-separated values (.csv) file to facilitate analysis.

Table 1. Sensors, attached to the electronic nose, and the gasses they are sensitive to.

\begin{tabular}{ccc}
\hline Sensor Name & Gases & Manufacturer \\
\hline MQ3 & Ethanol & \\
MQ4 & Methane & \\
MQ7 & Carbon monoxide $(\mathrm{CO})$ & \\
MQ8 & Hydrogen & Henan Hanwei Electronics Co., \\
MQ135 & Ammonia, alcohol, and benzene & Ltd., Henan, China \\
MQ136 & Hydrogen sulfide & \\
MQ137 & Ammonia & \\
MQ138 & Benzene, alcohol, and ammonia & \\
MG811 & Carbon dioxide $\left(\mathrm{CO}_{2}\right)$ & \\
\hline
\end{tabular}




\subsection{Chemical Analysis of Glycoconjugates and Volatile Phenols}

Volatile phenols (Table 2) were evaluated in wine samples using stable isotope dilution analysis (SIDA) methods, as previously described [15,17-19]. Isotopically labeled standards of $\mathrm{d}_{3}$-guaiacol, $\mathrm{d}_{3}$-4-methylguaiacol, $\mathrm{d}_{7}$-o-cresol, and $\mathrm{d}_{3}$-syringol were prepared in house by the Australian Wine Research Institute's (AWRI) Commercial Services Laboratory (Adelaide, Australia) using published methods [15,17,18]. Measurements were performed using an Agilent 6890 gas chromatography coupled to a 5973 mass-spectrometer (Agilent Technologies, Forest Hill, VIC, Australia). The limit of quantitation for volatile phenols was $1-2 \mu \mathrm{g} \mathrm{L} \mathrm{L}^{-1}$.

A range of volatile phenol glycoconjugates (Table 2) was measured using high-performance liquid chromatography-tandem mass spectrometry (HPLC-MS/MS) according to stable isotope dilution analysis (SIDA) methods previously described $[18,20]$. The analysis was performed using an Agilent 1200 high-performance liquid chromatography (HPLC) equipped with a 1290 binary pump, coupled to an AB SCIEX Triple QuadTM 4500 tandem mass spectrometer, with a Turbo VTM ion source (Framingham, MA, USA). The preparation of the isotopically labeled internal standard $\mathrm{d}_{3}$-syringol gentiobioside has been previously reported $[18,20]$. The limit of quantitation for volatile phenol glycosides was $1 \mu \mathrm{g} \mathrm{kg}^{-1}$.

Table 2. List of glycoconjugates and volatile phenols, their abbreviation, and the sample in which they were measured.

\begin{tabular}{|c|c|c|}
\hline Compound & Abbreviation/Label & Sample \\
\hline \multicolumn{3}{|c|}{ Glycoconjugates } \\
\hline Syringol gentiobiosides & SyGG & Berries/Wine \\
\hline Syringol glucosides & SyMG & Berries/Wine \\
\hline Syringol pentosylglucosides & SyPG & Berries/Wine \\
\hline Cresol glucosylpentosides & $\mathrm{CrPG}$ & Berries/Wine \\
\hline Cresol gentiobioside & CrGG & Berries \\
\hline Cresol glucosides & CrMG & Berries \\
\hline Cresol rutinosides & CrRG & Berries/Wine \\
\hline Guaiacol pentosylglucosides & GuPG & Berries/Wine \\
\hline Guaiacol gentiobiosides & GuGG & Berries/Wine \\
\hline Guaiacol rutinosides & GuRG & Berries/Wine \\
\hline Guaiacol glucosides & GuMG & Berries/Wine \\
\hline $\begin{array}{c}\text { Methylguaiacol } \\
\text { pentosylglucosides }\end{array}$ & MGuPG & Berries/Wine \\
\hline Methylguaiacol rutinosides & MGuRG & Berries/Wine \\
\hline Methylguaiacol glucosides & MGuMG & Berries \\
\hline Methylsyringol gentiobiosides & MSyGG & Berries/Wine \\
\hline $\begin{array}{c}\text { Methylsyringol } \\
\text { pentosylglucosides }\end{array}$ & MSyPG & Berries/Wine \\
\hline Phenol rutinosides & PhRG & Berries/Wine \\
\hline Phenol gentiobiosides & PhGG & Berries/Wine \\
\hline Phenol pentosylglucosides & PhPG & Berries/Wine \\
\hline Phenol glucosides & PhMG & Berries/Wine \\
\hline
\end{tabular}


Table 2. Cont.

\begin{tabular}{ccc}
\hline Compound & Abbreviation/Label & Sample \\
\hline Volatile Phenols & \\
\hline Guaiacol & Guaiacol & Berries/Wine \\
\hline Phenol & 4-Methylguaiacol & Berries/Wine \\
\hline$o$-Cresol & Phenol & Berries \\
\hline Total $m / p$-cresols & $o$-Cresol & Berries/Wine \\
\hline$m$-Cresol & Total $m / p$-cresol & Berries \\
\hline$p$-Cresol & $m$-Cresol & Berries/Wine \\
\hline Syringol & $p$-Cresol & Berries/Wine \\
\hline $4-$-Methylsyringol & Syringol & Berries/Wine \\
\hline Total cresols & 4 -Methylsyringol & Berries/Wine \\
\hline
\end{tabular}

\subsection{Sensory Evaluation-Consumer Test}

A consumer test was conducted with participants $(\mathrm{N}=31$; age range: $21-59$ years; $77 \%$ female and $23 \%$ male) constituted of staff and students from The University of Melbourne (UoM; Ethics ID: 1545786.2) that had been recruited via e-mail. According to the power analysis conducted using the SAS ${ }^{\circledR}$ Power and Sample Size v. 14.1 software (SAS Institute Inc., Cary, NC, USA), the number of participants was enough to find significant differences between samples (power: $1-\beta>0.99$ ). The session was carried out in the sensory laboratory of the Faculty of Veterinary and Agricultural Sciences (FVAS) in individual booths with uniform white light-emitting diode (LED) lights. Each booth was equipped with a tablet PC in which the Bio-Sensory Application (The University of Melbourne, Parkville, VIC, Australia) was set up with the questionnaire to gather consumer responses. The appearance, overall aroma, smoke aroma, bitterness, sweetness, acidity, astringency, a warming sensation, and overall liking were assessed on a likeness scale (i.e., dislike extremely—neither like nor dislike-like extremely). The levels of smoke aroma and perceived quality were rated on an intensity scale (i.e., absent-intense). Both liking and intensity measures were presented on a $15 \mathrm{~cm}$ non-structured continuous scale. In addition, emotional responses were recorded, using a $0-100$ FaceScale, where $0=$ sad $(\dot{\theta}$, $50=$ neutral $:-$, and $100=$ happy $(2)$. Samples were randomly assigned a 3-digit code, and $10 \mathrm{~mL}$ samples were served at room temperature $\left(20^{\circ} \mathrm{C}\right)$ in International Standard Wine Tasting Glasses (Bormioli Luigi, Fidenza, Italy). Samples were served in random order to avoid bias. Plain water and water crackers were used as palate cleansers between samples.

\subsection{Statistical Analysis and Machine Learning Modeling}

Analysis of variance (ANOVA) was conducted on e-nose data using XLSTAT (ver. 19.3.2, Addinsoft Inc., New York, NY, USA), and Tukey's honest significant difference test (HSD; $\alpha=0.05)$ was used to assess significant differences between treatments.

Machine learning modeling was performed based on artificial neural networks (ANN) for both pattern recognition and regression models, using codes written in Matlab ${ }^{\circledR}$ R2019b (Mathworks, Inc., Natick, MA, USA) developed to test 17 different training algorithms. Five distinct models were developed using 20 data points from the peak of the e-nose outputs (nine sensors) as inputs. Model 1 (pattern recognition) used the scaled conjugate gradient training algorithm to classify the wine samples into the five different treatments: (i) LS, (ii) HS, (iii) HSM, (iv) C, and (v) CM. All four regression models were developed using the Levenberg Marquardt algorithm. Model 2 consisted of the use of the 20 glycoconjugates and 10 volatile phenols (Table 2) found in berries one hour after being exposed to smoke as targets. In comparison, Model 3 used the same 20 glycoconjugates and 10 volatile phenols 
in berries but measured at harvest. The targets used for Model 4 were 17 glycoconjugates and seven volatile phenols analyzed in the wine samples (Table 2). On the other hand, Model 5 was developed to predict 12 sensory responses, using the liking of (i) appearance, (ii) overall aroma, (iii) smoke aroma, (iv) bitterness, (v) sweetness, (vi) acidity, (vii) astringency, (viii) a warming sensation, (ix) overall liking, and (x) the intensity of (i) smoke aroma, (ii) perceived quality, and (iii) the FaceScale emotional response as targets.

All inputs and targets were normalized from -1 to 1 . Data were divided randomly for all ANN models, with $60 \%$ of the data being used for the training stage, $20 \%$ for validation, and $20 \%$ for testing. Model 1 used a cross-entropy loss to test performance, while Models 2-5 were based on means squared error (MSE). Figure 1 shows the diagrams for Model A (Figure 1a), Models 2-4 (Figure 1b), and Model 5 (Figure 1c); all models consisted of a two-layer feedforward network with the hidden layer using a tan-sigmoid function and the output layer using softmax neurons (Model 1) and a linear transfer function (Models 2-5). A trimming test (data not shown) was performed to find the optimal number of neurons $(3,5,7,10)$ to get the best performance. Statistical data reported for regression models to assess under- or overfitting consist of the correlation coefficient (R), slope (b), MSE, and determination coefficient $\left(\mathrm{R}^{2}\right)$; the latter was calculated using the curve fitting tool found in Matlab ${ }^{\circledR}$.

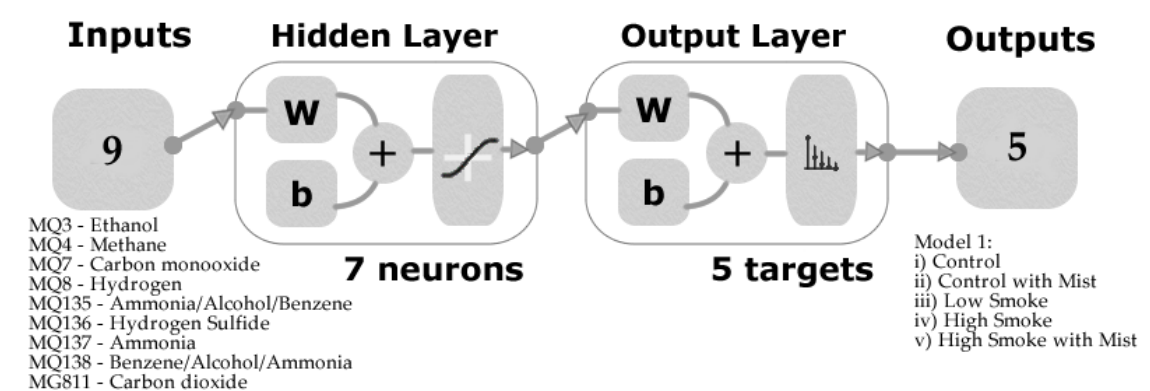

(a)

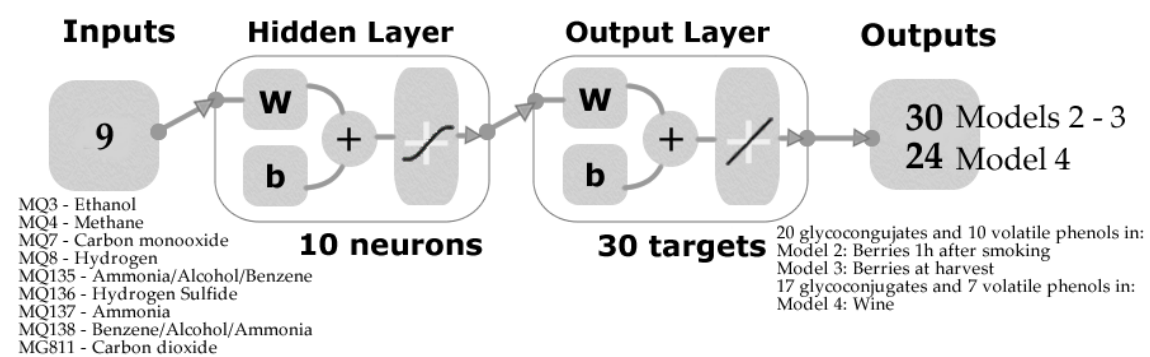

(b)

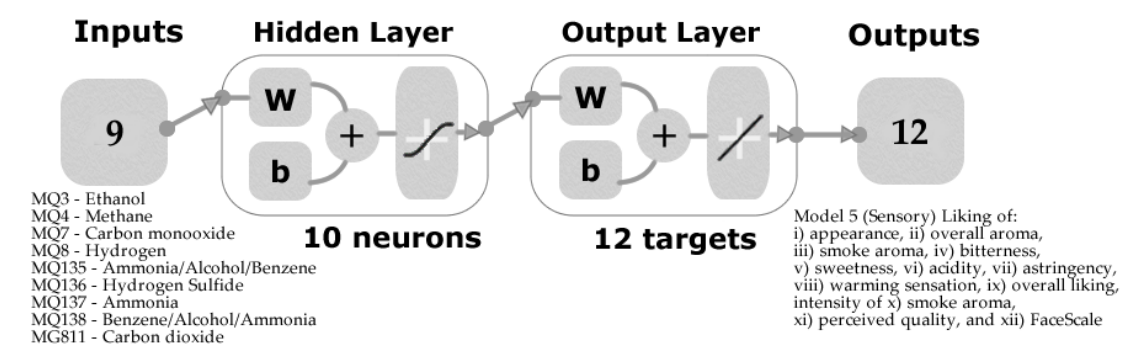

(c)

Figure 1. Model diagrams of the two-layer feedforward networks for (a) Model 1 for pattern recognition to classify samples into the five treatments using seven neurons, (b) Models 2-4 for regression to predict 20 glycoconjugates and 10 volatile phenols (Table 2) in Model 2: berries $1 \mathrm{~h}$ after smoke, Model 3: berries at harvest, and Model 4: wine, and (c) Model 5 for regression to predict 12 different sensory responses using 10 neurons. Abbreviations: W: weights, b: bias. 


\section{Results}

\subsection{Electronic Nose Results}

Figure 2 shows the results from the ANOVA for the e-nose responses. It can be observed that there were significant differences $(p<0.05)$ between samples in the outputs from all nine sensors that integrated the e-nose. Ethanol gas (MQ3) presented the highest values for all wine samples with $\mathrm{CM}($ mean $=4.07 \mathrm{~V})$ being significantly different from HSM $($ mean $=3.85 \mathrm{~V})$, HS $($ mean $=3.82 \mathrm{~V})$, and $C($ mean $=3.92 \mathrm{~V})$, and these from LS (mean $=3.66 \mathrm{~V})$. Hydrogen sulfide $(\mathrm{MQ136})$ was the lowest for all samples, and CM (mean $=0.34 \mathrm{~V}$ ) was significantly different from all other samples (means $=0.23-0.27 \mathrm{~V}$ ). The $\mathrm{CO}_{2}$ sensor readings are inverse; therefore, higher Volts mean lower concentration; it can be observed that all the samples with smoke treatments (LS, HS, and HSM) had the lowest $\mathrm{CO}_{2}$ and presented significant differences with control samples (CM and $\mathrm{C}$ ).

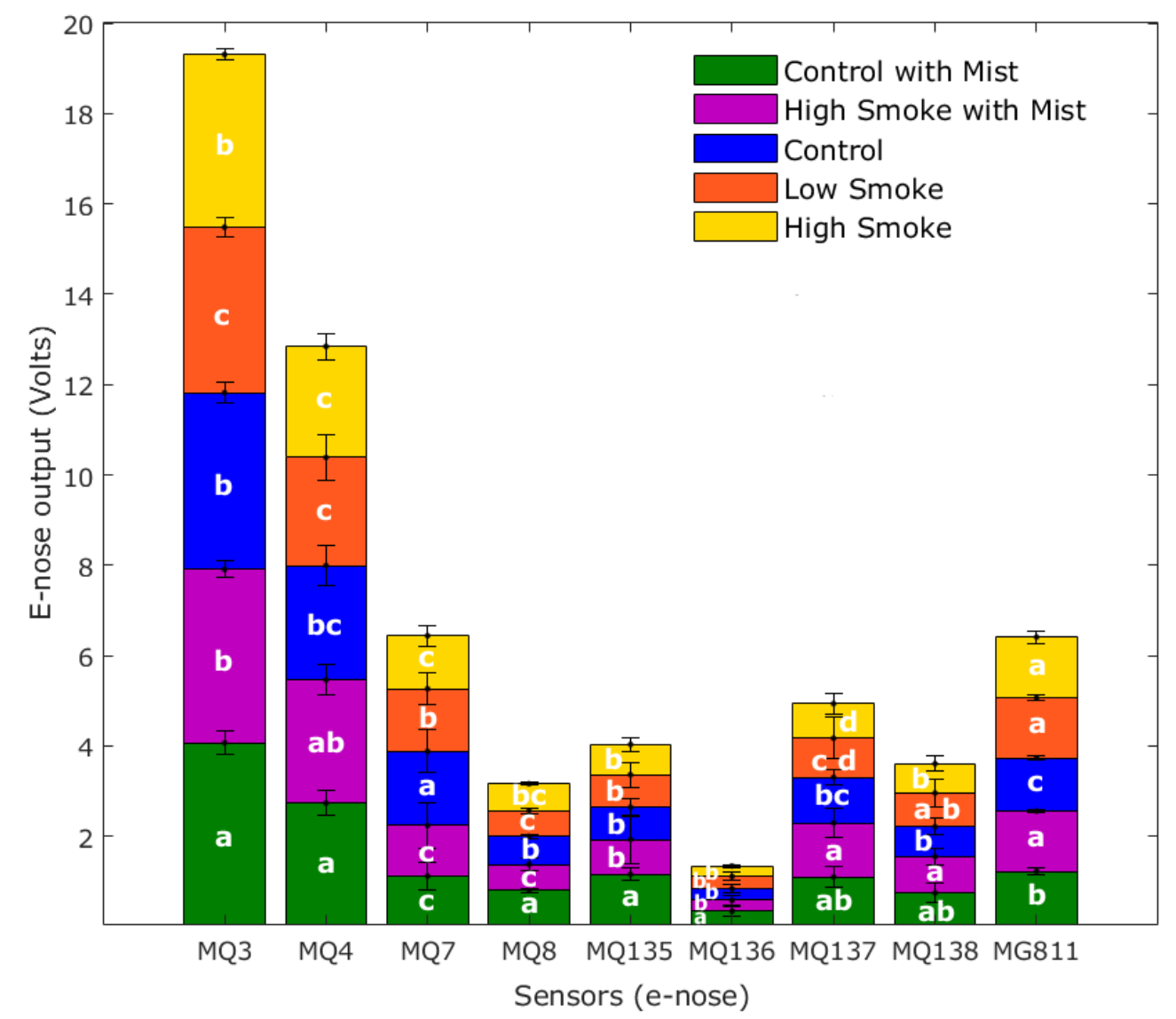

Figure 2. Mean values of the electronic nose outputs showing the letters of significance from the ANOVA and Tukey post hoc test $(\alpha=0.05)$. Sensors: MQ3 = ethanol, MQ4 = methane, $\mathrm{MQ7}=$ carbon monoxide, MQ8 = hydrogen, MQ135 = ammonia/alcohol/benzene, MQ136 = hydrogen sulfide, MQ137 = ammonia, MQ138 = benzene/alcohol/ammonia, MG811 = carbon dioxide.

Table 3 shows the minimum, maximum, and average values of the glycoconjugates and volatile phenols detected in berries one hour after smoking, in berries at harvest, and wine. It can be observed that there was a wide range of values for all of the compounds, which indicated these were adequate samples to be used for machine learning modeling and to detect smoke contamination. 
Table 3. Minimum (Min), maximum (Max), and mean values of the glycoconjugates (berries: $\mu \mathrm{g} \mathrm{kg}^{-1}$; wine: $\left.\mu \mathrm{g} \mathrm{L}^{-1}\right)$ and volatile phenols $\left(\mu \mathrm{g} \mathrm{L}^{-1}\right)$ detected in berries and wine.

\begin{tabular}{|c|c|c|c|c|c|c|c|c|c|}
\hline \multirow[t]{2}{*}{ Compound } & \multicolumn{3}{|c|}{$\begin{array}{c}\text { Berries } \\
1 \mathrm{~h} \text { After Smoking }\end{array}$} & \multicolumn{3}{|c|}{$\begin{array}{c}\text { Berries } \\
\text { at Harvest }\end{array}$} & \multicolumn{3}{|c|}{ Wine } \\
\hline & Min & Max & Mean & Min & Max & Mean & Min & Max & Mean \\
\hline Syringol gentiobioside & 2.37 & 56.93 & 15.42 & 6.30 & 772.81 & 186.55 & 10.43 & 582.11 & 152.58 \\
\hline Syringol monoglucoside & 0.14 & 26.97 & 6.38 & 2.65 & 68.34 & 19.22 & 0.36 & 14.54 & 4.26 \\
\hline Syringol pentosylglucosides & 0.76 & 4.52 & 1.79 & 6.41 & 369.14 & 88.76 & 1.70 & 103.37 & 27.73 \\
\hline Cresol glucosylpentosides & 8.07 & 47.12 & 18.13 & 41.69 & 1395.52 & 382.63 & 0.40 & 17.67 & 5.28 \\
\hline Cresol gentiobioside & 0.18 & 0.71 & 0.45 & 1.94 & 6.46 & 3.55 & NA & NA & NA \\
\hline Cresol monoglucoside & 0.24 & 61.87 & 16.36 & 0 & 35.47 & 8.70 & NA & NA & NA \\
\hline Cresol rutinoside & 1.62 & 13.34 & 4.90 & 3.11 & 122.07 & 38.35 & 2.91 & 133.85 & 40.55 \\
\hline Guaiacol pentosylglucosides & 2.29 & 25.61 & 7.57 & 15.76 & 1233.46 & 268.39 & 5.30 & 330.36 & 80.47 \\
\hline Guaiacol gentiobioside & 0.05 & 1.38 & 0.40 & 0.54 & 67.44 & 16.33 & 0.30 & 2.81 & 0.99 \\
\hline Guaiacol rutinoside & 0 & 1.35 & 0.48 & 1.13 & 32.03 & 9.97 & 0 & 48.60 & 15.24 \\
\hline Guaiacol monoglucoside & 0.03 & 30.04 & 7.07 & 1.22 & 30.25 & 7.15 & 0.12 & 12.60 & 3.46 \\
\hline Methylguaiacol pentosylglucosides & 0.55 & 11.51 & 3.29 & 6.79 & 266.50 & 57.32 & 1.43 & 51.79 & 12.72 \\
\hline Methylguaiacol rutinoside & 0.60 & 5.58 & 1.89 & 6.45 & 153.06 & 44.36 & 0.79 & 40.92 & 11.97 \\
\hline Methylguaiacol monoglucoside & 0 & 0 & 0 & 0.94 & 11.52 & 3.89 & NA & NA & NA \\
\hline Methylsyringol gentiobioside & 0.33 & 13.34 & 3.49 & 2.53 & 302.51 & 72.52 & 0.15 & 30.69 & 7.41 \\
\hline Methylsyringol pentosylglucosides & 0.07 & 0.39 & 0.17 & 1.57 & 34.84 & 10.36 & 0.20 & 8.35 & 2.46 \\
\hline Phenol rutinoside & 0.31 & 3.78 & 1.26 & 3.75 & 175.57 & 53.28 & 1.42 & 77.58 & 23.40 \\
\hline Phenol gentiobioside & 0.01 & 0.61 & 0.15 & 0 & 28.54 & 6.57 & 0.08 & 6.22 & 1.70 \\
\hline Phenol pentosylglucosides & 1.44 & 24.97 & 7.02 & 16.21 & 812.10 & 215.13 & 0.53 & 22.59 & 6.31 \\
\hline Phenol monoglucoside & 0.04 & 2.55 & 0.63 & 0.99 & 21.52 & 5.65 & 0.74 & 43.48 & 11.86 \\
\hline Guaiacol & 2.39 & 139.72 & 41.57 & 2.06 & 12.97 & 5.08 & 0 & 39.00 & 11.73 \\
\hline 4-Methylguaiacol & 3.54 & 27.72 & 9.50 & 3.52 & 4.45 & 3.80 & 0 & 5.00 & 1.40 \\
\hline Phenol & 1.40 & 85.68 & 21.12 & 1.26 & 26.38 & 9.61 & NA & NA & NA \\
\hline$o$-Cresol & 1.65 & 54.02 & 16.31 & 1.74 & 8.08 & 4.02 & 0 & 14.00 & 4.87 \\
\hline Total $m / p$-cresol & 0.56 & 63.07 & 16.01 & 0.52 & 7.71 & 2.99 & NA & NA & NA \\
\hline$m$-Cresol & 1.90 & 45.07 & 12.08 & 1.84 & 5.89 & 3.24 & 0 & 14.00 & 4.53 \\
\hline$p$-Cresol & 0 & 18.00 & 4.38 & 0 & 2.04 & 0.44 & 0 & 9.00 & 2.60 \\
\hline Syringol & 5.17 & 180.31 & 47.67 & 9.32 & 13.77 & 11.73 & 1.00 & 6.00 & 3.13 \\
\hline 4-Methylsyringol & 1.83 & 24.36 & 6.62 & 1.75 & 2.11 & 1.83 & 0 & 0 & 0 \\
\hline Total cresols & 2.22 & 117.08 & 32.32 & 2.26 & 15.79 & 7.01 & NA & NA & NA \\
\hline
\end{tabular}

Abbreviations: NA: Not applicable. Values $<1\left(\mu \mathrm{g} \mathrm{L}^{-1}\right.$ and $\left.\mu \mathrm{g} \mathrm{kg}^{-1}\right)$ are considered as below the limit of detection. However, actual values were included in the modeling strategies.

Table 4 shows the minimum, maximum, and average values of the responses from the sensory session conducted with consumers when evaluating the wines. It can be observed that the results from all attributes were within the whole range of the scales used for liking and appearance (0-15) and FaceScale (0-100), which made the data suitable to be used for machine learning modeling. 
Table 4. Minimum (Min), maximum (Max), and mean values of the sensory session responses for wine tasting.

\begin{tabular}{cccc}
\hline Data/Sensory Attribute & Min & Max & Mean \\
\hline Appearance liking & 0.45 & 15.00 & 7.19 \\
\hline Overall aroma liking & 0.30 & 14.85 & 6.21 \\
\hline Smoke aroma intensity & 0 & 15.00 & 4.98 \\
\hline Smoke aroma liking & 0 & 15.00 & 4.72 \\
\hline Bitter liking & 0.30 & 15.00 & 5.98 \\
\hline Sweet liking & 0 & 14.70 & 6.16 \\
\hline Acidity liking & 0 & 14.70 & 6.23 \\
\hline Astringency liking & 0.30 & 15.00 & 6.27 \\
\hline Warming liking & 0.30 & 15.00 & 6.20 \\
\hline Overall liking & 0.30 & 14.85 & 6.07 \\
\hline Perceived quality & 0 & 14.85 & 5.66 \\
\hline FaceScale & 0 & 99.00 & 42.15 \\
\hline
\end{tabular}

\subsection{Machine Learning Models}

Table 5 shows the statistical results from Model 1 for the classification of the samples into the five different treatments. It can be observed that there was a high accuracy for all stages (>90\%) and 97\% for the overall model. According to the performance values, there were no signs of overfitting, as the training stage had a cross-entropy value lower than the validation and testing, and these two had similar performance. In Figure 3, the results from the receiver operating characteristic (ROC) curve are shown. This graph depicted the sensitivity (true positive rate) and specificity (false positive rate) of the overall model, with optimal operating points of $98 \%, 100 \%, 93 \%, 93 \%$, and $98 \%$ for C, CM, LS, HS, and HSM, respectively.

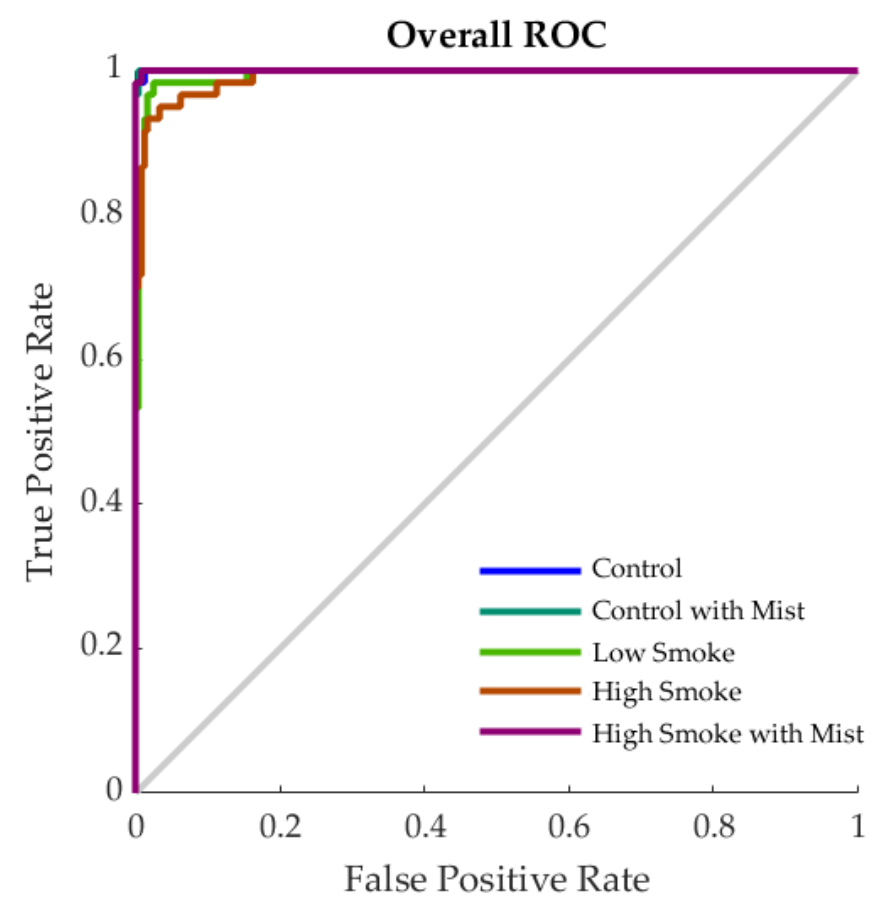

Figure 3. Receiver operating characteristic (ROC) curve for Model 1 to classify wine samples into the five different smoke treatments. 
Table 5. Statistical results from the pattern recognition model (Model 1) to classify samples into five different treatments (control, control with mist, low smoke, high smoke, and high smoke with mist).

\begin{tabular}{ccccc}
\hline $\begin{array}{c}\text { Stage } \\
\text { Model 1 }\end{array}$ & Samples & Accuracy & Error & $\begin{array}{c}\text { Performance } \\
\text { (Cross-Entropy) }\end{array}$ \\
\hline Training & 180 & $99 \%$ & $1 \%$ & 0.01 \\
\hline Validation & 60 & $93 \%$ & $7 \%$ & 0.04 \\
\hline Testing & 60 & $92 \%$ & $8 \%$ & 0.05 \\
\hline Overall & 300 & $97 \%$ & $3 \%$ & - \\
\hline
\end{tabular}

Table 6 depicts the statistical data for the four regression models. Model 2 had very high overall correlation and determination coefficients $\left(R=0.98\right.$; Figure $\left.4 a ; R^{2}=0.95\right)$. The close value of the validation and training correlation coefficients $(R=0.96$ and $R=0.98$, respectively), along with the fact that the performance of the training stage (MSE $=0.01)$ was lower than that of the validation and testing (MSE $=0.03$ and MSE $=0.02$, respectively), showed that there were no signs of under- or overfitting. Models 3 and 4 had similar statistical values, both with high accuracy (Model 3: $\mathrm{R}=0.99$; Figure $4 b ; R^{2}=0.97$; Model 4: $R=0.99$; Figure $4 c ; R^{2}=0.98$ ). These models also showed no signs of under- or overfitting. On the other hand, Model 5 also had a very high overall accuracy $(R=0.98$; Figure $4 d ; R^{2}=0.96$ ) with similar performance values for validation and testing (MSE $=0.04$ ) and higher than that of the training stage (MSE $=0.02$ ). All models presented a slope close to the unity $(b \sim 1)$ for all stages (Figure 4).

Table 6. Statistical results from the four regression models (Models 2-4: glycoconjugates and volatile phenols; Model 5: sensory) showing the correlation coefficient $(R)$, determination coefficient $\left(R^{2}\right)$, slope (b), and performance based on means squared error (MSE) for each stage.

\begin{tabular}{|c|c|c|c|c|c|c|}
\hline $\begin{array}{c}\text { Stage/ } \\
\text { Model } 2 \\
\text { (Berries } 1 \text { h Smoke) }\end{array}$ & Samples & Observations & $\mathbf{R}$ & $\mathbf{R}^{2}$ & $\mathbf{b}$ & $\begin{array}{l}\text { Performance } \\
\text { (MSE) }\end{array}$ \\
\hline Training & 180 & 5400 & 0.98 & 0.96 & 0.96 & 0.01 \\
\hline Validation & 60 & 1800 & 0.96 & 0.92 & 0.97 & 0.03 \\
\hline Testing & 60 & 1800 & 0.97 & 0.95 & 0.97 & 0.02 \\
\hline Overall & 300 & 9000 & 0.98 & 0.95 & 0.97 & - \\
\hline $\begin{array}{c}\text { Stage/ } \\
\text { Model } 3 \\
\text { (Berries at Harvest) }\end{array}$ & Samples & Observations & $\mathbf{R}$ & $\mathbf{R}^{2}$ & $\mathbf{b}$ & $\begin{array}{l}\text { Performance } \\
\text { (MSE) }\end{array}$ \\
\hline Training & 180 & 5400 & 0.99 & 0.98 & 0.97 & 0.01 \\
\hline Validation & 60 & 1800 & 0.98 & 0.95 & 0.96 & 0.02 \\
\hline Testing & 60 & 1800 & 0.98 & 0.97 & 0.95 & 0.01 \\
\hline Overall & 300 & 9000 & 0.99 & 0.97 & 0.96 & - \\
\hline $\begin{array}{l}\text { Stage/ } \\
\text { Model } 4 \\
\text { (Wine) }\end{array}$ & Samples & Observations & $\mathbf{R}$ & $\mathbf{R}^{2}$ & $\mathbf{b}$ & $\begin{array}{l}\text { Performance } \\
\text { (MSE) }\end{array}$ \\
\hline Training & 180 & 4320 & 0.99 & 0.99 & 0.99 & $<0.01$ \\
\hline Validation & 60 & 1440 & 0.98 & 0.95 & 0.96 & 0.02 \\
\hline Testing & 60 & 1440 & 0.98 & 0.96 & 0.95 & 0.01 \\
\hline Overall & 300 & 7200 & 0.99 & 0.98 & 0.98 & - \\
\hline
\end{tabular}


Table 6. Cont.

\begin{tabular}{ccccccc}
\hline $\begin{array}{c}\text { Stage/ } \\
\text { Model 5 } \\
\text { (Wine Sensory) }\end{array}$ & Samples & Observations & $\mathbf{R}$ & $\mathbf{R}^{\mathbf{2}}$ & $\mathbf{b}$ & $\begin{array}{c}\text { Performance } \\
\text { (MSE) }\end{array}$ \\
\hline Training & 180 & 2160 & 0.98 & 0.97 & 0.97 & 0.02 \\
\hline Validation & 60 & 720 & 0.97 & 0.94 & 0.97 & 0.04 \\
\hline Testing & 60 & 720 & 0.97 & 0.94 & 0.97 & 0.04 \\
\hline Overall & 300 & 3600 & 0.98 & 0.96 & 0.97 & - \\
\hline
\end{tabular}

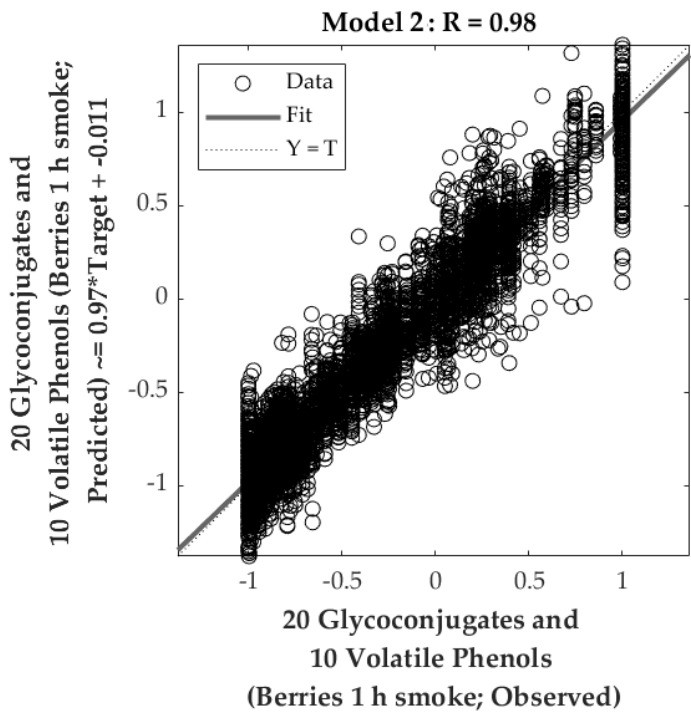

(a)

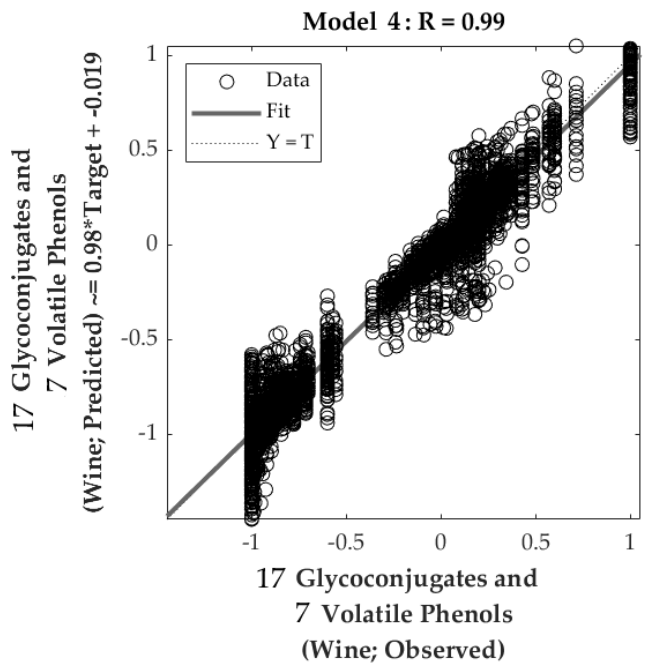

(c)

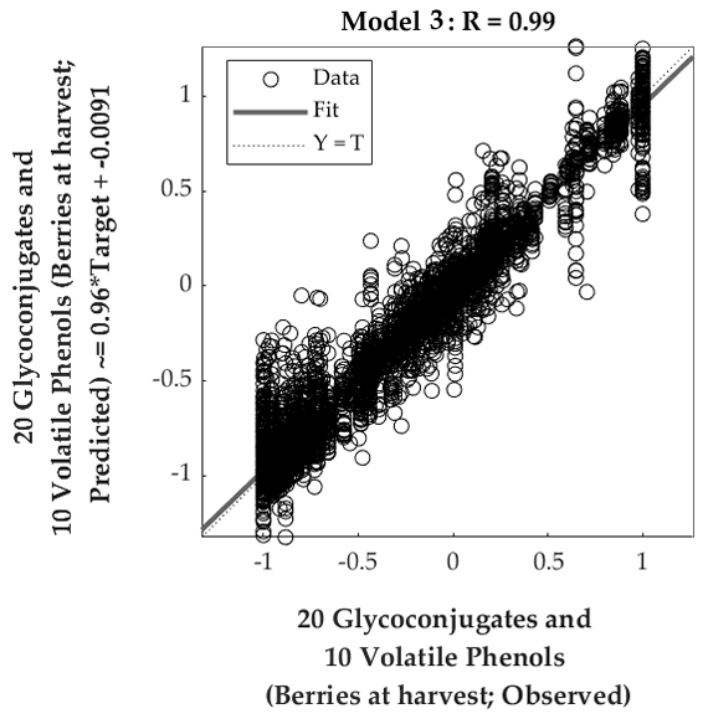

(b)

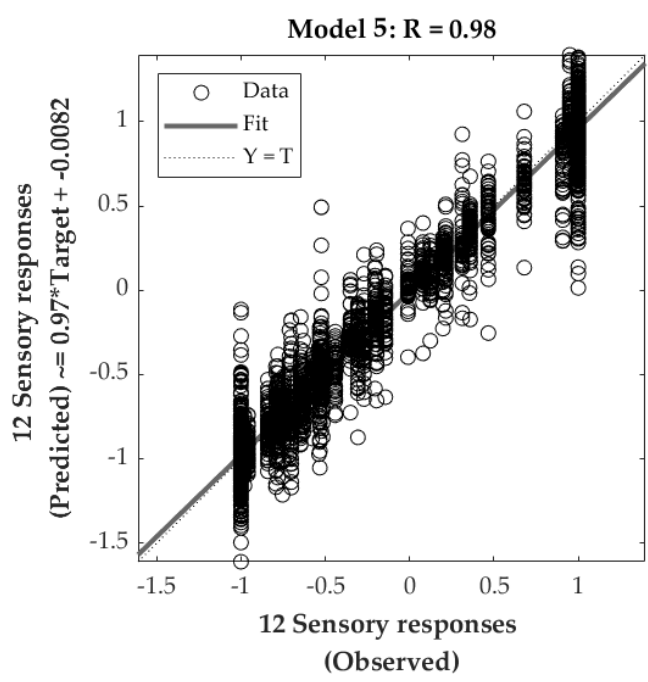

(d)

Figure 4. The overall correlation of the models to predict 20 glycoconjugates and 10 volatile phenols (Table 2) of (a) Model 2: berries after $1 \mathrm{~h}$ smoking, (b) Model 3: berries at harvest; (c) 17 glycoconjugates and seven volatile phenols of Model 4: wine. (d) Shows the Model 5 to predict 12 sensory descriptors obtained in a consumer test (Figure 1c). 


\section{Discussion}

Nowadays, the only alternative for grape growers is to apply potential amelioration techniques before the bushfires and hope for the best since there are limited tools that can be applied in the field or at the winemaking stage, which can render results in near real-time for proper decision-making $[35,36]$. Recently, non-invasive devices have been proposed using infrared thermal imaging to assess contaminated grapevine canopies in the field and smoke taint in berries and wines using near-infrared spectroscopy [5,33]. The research presented in this paper has contributed to the potential implementation of new and emerging sensor technologies and modeling strategies using machine learning in the viticulture and winemaking industry. These low-cost e-noses could become a game-changer for the management of smoke contamination and taint in berries and wines due to bushfires.

In general, previous applications of e-noses in the wine industry have been implemented mainly for the analysis of grapes and crushing methods [37], improvement of maceration and fermentation processes [38], to monitor the aging of wine in barrels [39-41], geographical classification [42], wine spoilage $[28,43,44]$, and to assess correlations with human perception through sensory evaluation $[27,29,45]$. However, most of these studies have been based on multivariate data analysis and correlation analysis.

Low-cost sensors presented in this research, developed by integrating an array of gas sensors [20], could be used in the winery to assess the level of grapevine smoke exposure. In the present study, models were developed to evaluate the effects of different amelioration techniques (Model 1) for berries immediately after the bushfire event (Model 2), at harvest time (Model 3), and in the actual wines (Model 4). Since smoke-derived glycoconjugates in berries are difficult to detect using e-noses due to the binding of these compounds with sugars in the berries, these assessments need to be performed after the winemaking process, in which the compounds are released through the maceration and fermentation processes.

A further model (Model 5) developed to assess sensory characteristics of wines rapidly and objectively, which can be implemented in parallel with successful amelioration techniques to reduce smoke taint, such as the addition of activated carbon to wines or fining agents [2,34]. For the latter case, Model 5 will offer a near real-time assessment of the techniques used.

The advantages of implementing these models coupled with low-cost sensor technology are that grape growers and winemakers will not depend on random sampling, which may not render representative results, or external laboratory services, which may not deliver results in a timely manner due to being overwhelmed by large sample volumes that are delivered when concurrent bushfires occur. Knowing the levels of smoke-derived compounds and the effects on consumer appreciation in the winemaking process offer the following advantages: (i) rapid and user-friendly smoke taint determination; (ii) potential implementation of techniques to reduce smoke taint using activated carbon or fining agents on samples and re-test using the e-nose and models developed; (iii) sensory panel not required for assessments/modifications, minimizing the time for the commercial release of wines and economic impacts of smoke taint.

Further applications of these low-cost e-noses can be implemented to assess the maturity of grapes in the field, specifically through the alcohol-based sensors. The latest research has shown that ethanol is released from grape berries when they become oxygen stressed [46]. So, being able to assess when cell death begins would be a useful tool in monitoring berry health and fruit ripening potential. These processes of berry cell death assessment can be done non-destructively by near-infrared spectroscopy and machine learning modeling [47] or by tracking ethanol release from grapevine bunches through the implementation of low-cost e-noses in the field using sensor networks or as a payload of low altitude unmanned aerial vehicle (UAV) surveys [48,49]. 


\section{Conclusions}

Low-cost e-nose sensor technology coupled with machine learning offers the advantage of easy implementation in field conditions using sensor networks or in the winery. Machine learning models obtained could make available valuable information to winemakers and winegrowers for the decision-making process to produce commercial wines by minimizing smoke taint. An artificial intelligence system can be implemented based on sensor technology and machine learning developed here to obtain the least tainted wine or to target specific sensory aroma profiles to take advantage of the decontamination process to maximize the likability of wines.

Author Contributions: Conceptualization, S.F. and C.G.V.; Data curation, S.F. and C.G.V.; Formal analysis, C.G.V.; Funding acquisition, R.R.U.; Investigation, S.F., V.S., C.G.V. and K.L.W.; Methodology, V.S., C.G.V., K.L.W., C.S. and R.R.U.; Project administration, S.F., C.G.V., and K.L.W.; Resources, S.F. and R.R.U.; Software, S.F., C.G.V. and R.R.U.; Supervision, S.F.; Validation, S.F., C.G.V. and N.L.; Visualization, S.F., C.G.V. and E.T.; Writing-original draft, S.F. and C.G.V.; Writing-review and editing, S.F., V.S., C.G.V., E.T., N.L., K.L.W., C.S. and R.R.U. All authors have read and agreed to the published version of the manuscript.

Funding: This research was supported by the Australian Research Councils Linkage Projects funding scheme (LP160101475).

Acknowledgments: The authors would like to acknowledge Bryce Widdicombe, Mimi Sun, and Jorge Gonzalez for their collaboration in the electronic nose development. C.S. was supported by the Australian Research Council Training Centre for Innovative Wine Production (www.arcwinecentre.org.au), which is part of the ARC's Industrial Transformation Research Program (Project No. ICI70100008), with support from Wine Australia and industry partners.

Conflicts of Interest: The authors declare no conflict of interest.

\section{References}

1. Kennison, K.; Wilkinson, K.L.; Pollnitz, A.; Williams, H.; Gibberd, M.R. Effect of smoke application to field-grown Merlot grapevines at key phenological growth stages on wine sensory and chemical properties. Aust. J. Grape Wine Res. 2011, 17, S5-S12. [CrossRef]

2. Ristic, R.; Fudge, A.L.; Pinchbeck, K.A.; De Bei, R.; Fuentes, S.; Hayasaka, Y.; Tyerman, S.D.; Wilkinson, K.L. Impact of grapevine exposure to smoke on vine physiology and the composition and sensory properties of wine. Theor. Exp. Plant Physiol. 2016, 28, 67-83. [CrossRef]

3. Szeto, C.; Ristic, R.; Capone, D.; Puglisi, C.; Pagay, V.; Culbert, J.; Jiang, W.; Herderich, M.; Tuke, J.; Wilkinson, K. Uptake and Glycosylation of Smoke-Derived Volatile Phenols by Cabernet Sauvignon Grapes and Their Subsequent Fate during Winemaking. Molecules 2020, 25, 3720. [CrossRef] [PubMed]

4. Bruyère, C.; Holland, G.; Prein, A.; Done, J.; Buckley, B.; Chan, P.; Leplastrier, M.; Dyer, A. Severe Weather in a Changing Climate; Insurance Australia Group and National Center for Atmospheric Research, November. Insurance Australia Group Limited, 2019. Available online: https://www.iag.com.au/sites/default/files/ documents/Severe-weather-in-a-changing-climate-report-011119.pdf (accessed on 3 August 2020).

5. Fuentes, S.; Tongson, E.J.; De Bei, R.; Gonzalez Viejo, C.; Ristic, R.; Tyerman, S.; Wilkinson, K. Non-Invasive Tools to Detect Smoke Contamination in Grapevine Canopies, Berries and Wine: A Remote Sensing and Machine Learning Modeling Approach. Sensors 2019, 19, 3335. [CrossRef]

6. Dungey, K.A.; Hayasaka, Y.; Wilkinson, K.L. Quantitative analysis of glycoconjugate precursors of guaiacol in smoke-affected grapes using liquid chromatography-tandem mass spectrometry based stable isotope dilution analysis. Food Chem. 2011, 126, 801-806. [CrossRef]

7. Hayasaka, Y.; Parker, M.; Baldock, G.A.; Pardon, K.H.; Black, C.A.; Jeffery, D.W.; Herderich, M.J. Assessing the impact of smoke exposure in grapes: Development and validation of a HPLC-MS/MS method for the quantitative analysis of smoke-derived phenolic glycosides in grapes and wine. J. Agric. Food Chem. 2012, 61, 25-33. [CrossRef]

8. Cipriano, D.; Capelli, L. Evolution of Electronic Noses from Research Objects to Engineered Environmental Odour Monitoring Systems: A Review of Standardization Approaches. Biosensors 2019, 9, 75. [CrossRef]

9. Wilson, D.M.; DeWeerth, S.P. Odor discrimination using steady-state and transient characteristics of tin-oxide sensors. Sens. Actuators B Chem. 1995, 28, 123-128. [CrossRef] 
10. Roussel, S.; Forsberg, G.; Steinmetz, V.; Grenier, P.; Bellon-Maurel, V. Optimisation of electronic nose measurements. Part I: Methodology of output feature selection. J. Food Eng. 1998, 37, 207-222. [CrossRef]

11. Carmel, L.; Levy, S.; Lancet, D.; Harel, D. A feature extraction method for chemical sensors in electronic noses. Sens. Actuators B Chem. 2003, 93, 67-76. [CrossRef]

12. Ayhan, B.; Kwan, C.; Zhou, J.; Kish, L.B.; Benkstein, K.D.; Rogers, P.H.; Semancik, S. Fluctuation enhanced sensing (FES) with a nanostructured, semiconducting metal oxide film for gas detection and classification. Sens. Actuators B Chem. 2013, 188, 651-660. [CrossRef]

13. Wojnowski, W.; Dymerski, T.; Gębicki, J.; Namieśnik, J. Electronic noses in medical diagnostics. Curr. Med. Chem. 2019, 26, 197-215. [CrossRef] [PubMed]

14. Young, R.C.; Buttner, W.J.; Linnell, B.R.; Ramesham, R. Electronic nose for space program applications. Sens. Actuators B Chem. 2003, 93, 7-16. [CrossRef]

15. Ryan, M.A.; Zhou, H.; Buehler, M.G.; Manatt, K.S.; Mowrey, V.S.; Jackson, S.P.; Kisor, A.K.; Shevade, A.V.; Homer, M.L. Monitoring space shuttle air quality using the jet propulsion laboratory electronic nose. IEEE Sens. J. 2004, 4, 337-347. [CrossRef]

16. Li, W.; Leung, H.; Kwan, C.; Linnell, B.R. E-nose vapor identification based on Dempster-Shafer fusion of multiple classifiers. IEEE Trans. Instrum. Meas. 2008, 57, 2273-2282. [CrossRef]

17. Peveler, W.J.; Parkin, I.P. Electronic Noses: The Chemistry of Smell and Security; Wortley, R., Sidebottom, A., Tilley, N., Laycock, Eds.; Routledge: Abingdon, Oxon, UK; New York, NY, USA, 2019; pp. 384-392. ISBN 9780415826266. [CrossRef]

18. Rusinek, R.; Siger, A.; Gawrysiak-Witulska, M.; Rokosik, E.; Malaga-Toboła, U.; Gancarz, M. Application of an electronic nose for determination of pre-pressing treatment of rapeseed based on the analysis of volatile compounds contained in pressed oil. Int. J. Food Sci. Tech. 2020, 55, 2161-2170. [CrossRef]

19. Liu, H.; Li, Q.; Yan, B.; Zhang, L.; Gu, Y. Bionic Electronic Nose Based on MOS Sensors Array and Machine Learning Algorithms Used for Wine Properties Detection. Sensors 2019, 19, 45. [CrossRef]

20. Gonzalez Viejo, C.; Fuentes, S.; Godbole, A.; Widdicombe, B.; Unnithan, R.R. Development of a low-cost e-nose to assess aroma profiles: An artificial intelligence application to assess beer quality. Sens. Actuators $B$ Chem. 2020, 308, 127688. [CrossRef]

21. Gardner, J.W.; Bartlett, P.N. A brief history of electronic noses. Sens. Actuators B Chem. 1994, 18, $210-211$. [CrossRef]

22. Turner, A.P.; Magan, N. Electronic noses and disease diagnostics. Nat. Rev. Microbiol. 2004, 2, 161-166. [CrossRef]

23. Schaller, E.; Bosset, J.O.; Escher, F. 'Electronic noses' and their application to food. Lebensm-Wiss Technol 1998, 31, 305-316. [CrossRef]

24. Wojnowski, W.; Majchrzak, T.; Dymerski, T.; Gębicki, J.; Namieśnik, J. Electronic noses: Powerful tools in meat quality assessment. Meat. Sci. 2017, 131, 119-131. [CrossRef] [PubMed]

25. Peris, M.; Escuder-Gilabert, L. Electronic noses and tongues to assess food authenticity and adulteration. Trends Food Sci. Technol. 2016, 58, 40-54. [CrossRef]

26. Rodríguez-Méndez, M.L.; De Saja, J.A.; González-Antón, R.; García-Hernández, C.; Medina-Plaza, C.; García-Cabezón, C.; Martín-Pedrosa, F. Electronic noses and tongues in wine industry. Front. Bioeng. Biotechnol. 2016, 4, 81. [CrossRef] [PubMed]

27. Lozano, J.; Santos, J.P.; Horrillo, M.C. Electronic Noses and Tongues in Food Science; Rodríguez Méndez, M.L., Ed.; Elsevier: Cambridge, MA, USA, 2016; pp. 137-148, 301-307. ISBN 9780128002438. [CrossRef]

28. Gamboa, J.C.R.; da Silva, A.J.; de Andrade Lima, L.L.; Ferreira, T.A. Wine quality rapid detection using a compact electronic nose system: Application focused on spoilage thresholds by acetic acid. LWT 2019, 108, 377-384. [CrossRef]

29. Gardner, D.M.; Duncan, S.E.; Zoecklein, B.W. Aroma characterization of Petit Manseng wines using sensory consensus training, SPME GC-MS, and electronic nose analysis. Am. J. Enol. Vitic. 2017, 68, 112-119. [CrossRef]

30. Han, F.; Zhang, D.; Aheto, J.H.; Feng, F.; Duan, T. Integration of a low-cost electronic nose and a voltammetric electronic tongue for red wines identification. J. Food Sci. 2020, 8, 4330-4339. [CrossRef]

31. Fan, H.; Hernandez Bennetts, V.; Schaffernicht, E.; Lilienthal, A.J. Towards gas discrimination and mapping in emergency response scenarios using a mobile robot with an electronic nose. Sensors 2019, 19, 685. [CrossRef] 
32. Valente, J.; Almeida, R.; Kooistra, L. A Comprehensive Study of the Potential Application of Flying Ethylene-Sensitive Sensors for Ripeness Detection in Apple Orchards. Sensors 2019, 19, 372. [CrossRef]

33. Van der Hulst, L.; Munguia, P.; Culbert, J.A.; Ford, C.M.; Burton, R.A.; Wilkinson, K.L. Accumulation of volatile phenol glycoconjugates in grapes following grapevine exposure to smoke and potential mitigation of smoke taint by foliar application of kaolin. Planta 2019, 249, 941-952. [CrossRef]

34. Fudge, A.; Schiettecatte, M.; Ristic, R.; Hayasaka, Y.; Wilkinson, K.L. Amelioration of smoke taint in wine by treatment with commercial fining agents. Aust. J. Grape Wine Res. 2012, 18, 302-307. [CrossRef]

35. Fudge, A.; Ristic, R.; Wollan, D.; Wilkinson, K.L. Amelioration of smoke taint in wine by reverse osmosis and solid phase adsorption. Aust. J. Grape Wine Res. 2011, 17, S41-S48. [CrossRef]

36. Ristic, R.; Osidacz, P.; Pinchbeck, K.; Hayasaka, Y.; Fudge, A.; Wilkinson, K.L. The effect of winemaking techniques on the intensity of smoke taint in wine. Aust. J. Grape Wine Res. 2011, 17, S29-S40. [CrossRef]

37. Prieto, N.; Gay, M.; Vidal, S.; Aagaard, O.; De Saja, J.; Rodriguez-Mendez, M. Analysis of the influence of the type of closure in the organoleptic characteristics of a red wine by using an electronic panel. Food Chem. 2011, 129, 589-594. [CrossRef] [PubMed]

38. Pinheiro, C.; Rodrigues, C.M.; Schäfer, T.; Crespo, J.G. Monitoring the aroma production during wine-must fermentation with an electronic nose. Biotechnol Bioeng 2002, 77, 632-640. [CrossRef]

39. Wei, Y.J.; Yang, L.L.; Liang, Y.P.; Li, J.M. Application of electronic nose for detection of wine-aging methods. Adv. Mater. Res. 2014, 875-877, 2206-2213. [CrossRef]

40. Apetrei, I.; Rodríguez-Méndez, M.; Apetrei, C.; Nevares, I.; Del Alamo, M.; De Saja, J. Monitoring of evolution during red wine aging in oak barrels and alternative method by means of an electronic panel test. Food Res. Int. 2012, 45, 244-249. [CrossRef]

41. Lozano, J.; Arroyo, T.; Santos, J.; Cabellos, J.; Horrillo, M. Electronic nose for wine ageing detection. Sens. Actuators B Chem. 2008, 133, 180-186. [CrossRef]

42. Cynkar, W.; Dambergs, R.; Smith, P.; Cozzolino, D. Classification of Tempranillo wines according to geographic origin: Combination of mass spectrometry based electronic nose and chemometrics. Anal. Chim. Acta 2010, 660, 227-231. [CrossRef]

43. Macías, M.M.; Manso, A.G.; Orellana, C.J.G.; Velasco, H.M.G.; Caballero, R.G.; Chamizo, J.C.P. Acetic acid detection threshold in synthetic wine samples of a portable electronic nose. Sensors 2013, 13, 208-220. [CrossRef]

44. Wang, H.; Hu, Z.; Long, F.; Guo, C.; Yuan, Y.; Yue, T. Early detection of Zygosaccharomyces Rouxii-spawned spoilage in apple juice by electronic nose combined with chemometrics. Int. J. Food Microbiol. 2016, 217, 68-78. [CrossRef] [PubMed]

45. Aleixandre, M.; Cabellos, J.M.; Arroyo, T.; Horrillo, M. Quantification of Wine Mixtures with an electronic nose and a human Panel. Front. Bioeng. Biotechnol. 2018, 6, 14. [CrossRef] [PubMed]

46. Xiao, Z.; Rogiers, S.Y.; Sadras, V.O.; Tyerman, S.D. Hypoxia in grape berries: The role of seed respiration and lenticels on the berry pedicel and the possible link to cell death. J. Exp. Bot. 2018, 69, 2071-2083. [CrossRef] [PubMed]

47. Fuentes, S.; Tongson, E.; Chen, J.; Gonzalez Viejo, C. A Digital Approach to Evaluate the Effect of Berry Cell Death on Pinot Noir Wines' Quality Traits and Sensory Profiles Using Non-Destructive Near-Infrared Spectroscopy. Beverages 2020, 6, 39. [CrossRef]

48. Valente, J.; Munniks, S.; de Man, I.; Kooistra, L. Validation of a small flying e-nose system for air pollutants control: A plume detection case study from an agricultural machine. In Proceedings of the 2018 IEEE International Conference on Robotics and Biomimetics (ROBIO), Kuala Lumpur, Malaysia, 12-15 December 2018; pp. 1993-1998.

49. Muralidhara, B.; Geethanjali, B. Review on different technologies used in Agriculture. Int. J. Pure Appl. Math. 2018, 119, 4117-4134.

(C) 2020 by the authors. Licensee MDPI, Basel, Switzerland. This article is an open access article distributed under the terms and conditions of the Creative Commons Attribution (CC BY) license (http://creativecommons.org/licenses/by/4.0/). 